\title{
Regional anaesthesia for surgical treatment of inguinal hernia in preterm babies
}

Preterm infants requiring general anaesthesia in the first few months of life have a higher incidence of postoperative complications than term infants. ${ }^{1}$ Thus it has been recommended that elective surgery should be postponed in these infants until they are no longer at risk of developing these problems. $^{2}$ However, the optimal timing of surgery remains difficult to determine and it depends very much on the individual infant's perinatal history, maturity, and the presence of other illnesses. ${ }^{3}$

Inguinal hernia is a common surgical condition in this group, ${ }^{4}$ occurring in up to one third infants of birth weight $<1000$ g. ${ }^{5}$ Early surgical repair has been recommended as delay may result in incarceration of the hernia, bowel ischaemia, and gonadal infarction. ${ }^{6}$

The dilemma posed by the need for early surgery coupled with the risks of general anaesthesia may be resolved by the use of a regional anaesthetic technique in the awake infant.

\section{Preterm infants and general anaesthesia}

Respiratory problems are the most serious complications occurring in former preterm infants after general anaesthesia. The reported incidence of apnoea varies from $18 \%{ }^{1}$ to $37 \%^{7}$ depending on the indication for surgery, the general health of the infant, and the method used to identify apnoea. In a prospective study, using pneumography, Welborn et al found that $37 \%$ of healthy former preterm infants undergoing inguinal hernia repair developed periodic breathing postoperatively. ${ }^{8}$ In a later study of a similar group, eight out of 11 preterm infants had episodes of prolonged apnoea in the postoperative period. ${ }^{9}$ Kurth and LeBard found that $24 \%$ of preterm infants had apnoea after inguinal herniotomy. ${ }^{10}$ The majority of apnoeas are self limiting or respond to simple manual stimulation, but ventilatory support postoperatively may be required. ${ }^{11}$ The risk of developing apnoea is inversely related to the postconceptional age being more common in infants with a postconceptional age $<44-46$ weeks, ${ }^{7810}$ but has been reported in older infants ${ }^{7}$ and may be related to anaemia. ${ }^{12}$ It cannot be predicted reliably by a previous history of apnoea or by preoperative pneumography. ${ }^{10}$

The pathogenesis of postoperative apnoea is multifactorial and involves an abnormality of central respiratory control and airway obstruction. ${ }^{10}$ The majority occur in the immediate postoperative period, which may reflect the depressant effects of low concentrations of general anaesthetic agents on respiratory drive $\mathrm{e}^{13}$ and the residual effects of muscle relaxants on upper airway tone. ${ }^{14}$ However, the mechanism of late onset apnoea occurring 2-12 hours after surgery is unclear and may be related to the respiratory depressant effect of high levels of endorphins. ${ }^{15}$

Although Welborn et al have demonstrated that caffeine $10 \mathrm{mg} / \mathrm{kg}$, administered at induction of anaesthesia, diminishes the incidence of postoperative apnoea, ${ }^{16}$ these infants are still at risk from the respiratory complications of intubation and ventilation. ${ }^{17}$ Furthermore, it is our impression, and this has also been observed in other centres, ${ }^{18}$ that infants with bronchopulmonary dysplasia who develop any of these problems, and who need ventilation postoperatively, are difficult to wean and suffer a setback in their overall recovery.

\section{Spinal anaesthesia}

In view of the problems associated with general anaesthesia Abajian et al ${ }^{19}$ proposed the use of spinal anaesthesia for former preterm infants requiring inguinal herniotomy and the technique is now widely accepted..$^{20-22}$ It involves subarachnoid injection of local anaesthetic through a small (25 gauge) lumbar puncture needle inserted at the L4-L5 or L5-SI interspace. Hyperbaric bupivacaine $0.5 \%$ or hyperbaric tetracaine $1 \%$ are the most commonly used drugs for spinal anaesthesia. There is no reliable method of estimating the extent of sensory loss in these patients but adequate blockade is usually heralded by the rapid onset of flaccid paralysis of the lower limbs after administration of the drug. In infants, unlike adults, cardiovascular stability is usually maintained and may be due to immaturity of the sympathetic nervous system. ${ }^{23}$ When spinal anaesthesia is established the infants either sleep or are easily placated with a soother and surgery can proceed. Since 1987 we have used it for inguinal surgery in these babies and find it satisfactory in the majority of patients. However, spinal anaesthesia is of short duration in infants, due possibly to differences in cerebrospinal fluid dynamics and in our experience is only suitable for procedures lasting less than 60 minutes. If surgery is unduly prolonged it may be necessary to supplement the anaesthesia with intravenous sedation, which increases the risk of apnoea. ${ }^{22}$

Although several studies have demonstrated the potential safety of spinal anaesthesia, ${ }^{19-22}$ monitoring is required for an appropriate period after surgery as the risk of apnoea is still present in these infants. ${ }^{24} 25$

The advantages of spinal anaesthesia are that it causes minimal physiological disturbance, avoids the risks of general anaesthesia, and allows prompt return to preoperative feeding schedules.

\section{Caudal epidural anaesthesia}

Caudal epidural anaesthesia is widely used in paediatric practice as a supplement to general anaesthesia and for postoperative pain relief. Recently, it has been advocated as the sole anaesthetic technique in the awake premature infant needing inguinal surgery. ${ }^{26-28}$ It involves puncture of the sacrococcygeal ligament and injection of local anaesthetic, usually bupivacaine $0 \cdot 25 \%$ with $1: 200000$ adrenaline, into the caudal space with onset of surgical anaesthesia within 20 minutes. Hazards inherent in the technique itself include the risk of dural puncture with subarchnoid injection of a large volume of local anaesthetic, and inadvertent intravenous injection. In our experience it is a useful alternative to spinal anaesthesia, is longer lasting, and provides postoperative analgesia.

\section{Recommendations}

Preterm infants needing inguinal herniotomy pose many problems for paediatric anaesthetists. The aim is to provide satisfactory surgical conditions with adequate anaesthesia while causing minimal physiological disturbance and rapid recovery to the preanaesthetic status. The complications associated with general anaesthesia are well recognised and an unsupplemented regional anaesthetic technique seems to be closest to the ideal. However these procedures are not without hazard, and may be associated 
with serious complications. Therefore, vigilance by the anaesthetist is required during these procedures and throughout the operative period.

If the inguinal hernia is reducible, it is our practice, in common with other centres, ${ }^{6}$ to defer surgery until the overall condition of the infant is stable. Herniotomy is usually performed before discharge from the neonatal intensive care unit. If an infant, who has already been discharged home, develops a hernia, surgery is performed within 24 hours and the infant is admitted to hospital for overnight monitoring.

It must be emphasised that, irrespective of the anaesthetic technique used, all infants with a postconceptional age $<44-46$ weeks should have apnoea monitoring for 12 hours postoperatively. ${ }^{3}$ It is our practice to use similar monitoring in infants with a postconceptional age $<60$ weeks, and we do not consider them suitable for day surgery. As these infants represent a high risk it would seem prudent to refer them for management by paediatric anaesthetists and paediatric surgeons. Surgery should be performed in a centre capable of providing adequate postoperative care and if necessary postoperative ventilation.

T M GALLAGHER

Paediatric Intensive Care Unit,

Royal Belfast Hospital for Sick Children,

Belfast BT12 6BE

1 Steward DJ. Preterm infants are more prone to complications following minor surgery than are term infants. Anesthesiology 1982; 56: 304-6.

2 Gregory GA, Steward DJ. Life-threatening perioperative apnea in the ex'premie'. Anesthesiology 1983; 59: 495-8.

3 Welborn LG. Postoperative apnoea in the former preterm infant: a review. Paediatric Anaesthesia 1992; 2: 37-44.

4 Boocock GR, Todd PJ. Inguinal hernias are common in preterm infants. Arch Dis Child 1985; 60: 669-70.

5 Harper RG, Garcia A, Sia C. Inguinal hernia: a common problem of premature infants weighing 1000 grams or less at birth. Pediatrics 1975; 56: 112-5. 6 Rescorla FJ, Grosfeld JL. Inguinal hernia repair in the perinatal period and early infancy: clinical considerations. $\mathcal{F}$ Pediatr Surg 1984; 19: 832-7.

7 Kurth CD, Spitzer AR, Broennle AM, Downes JJ. Postoperative apnea in preterm infants. Anesthesiology $1987 ; 66: 483-8$.
8 Welborn LG, Ramirez N, Oh TH, et al. Postanesthetic apnea and periodic breathing in infants. Anesthesiology 1986; 65: 658-61.

9 Welborn LG, De Soto H, Hannallah RS, Fink R, Ruttimann UE, Boeckx R The use of caffeine in the control of postanesthetic apnea in former preThe use of caffeine in the control of postanesthe

10 Kurth CD, LeBard SE. Association of postoperative apnea, airway obstruction, and hypoxemia in former premature infants. Anesthesiology 1991; 75: 22-6.

11 Liu LMP, Cote CJ, Goudsouzian NG, et al. Life-threatening apnea in infants recovering from anesthesia. Anesthesiology 1983; 59: 506-10.

12 Welborn LG, Hannallah RS, Luban NL, Fink R, Ruttiman UE. Anemia and postoperative apnea in former preterm infants. Anesthesiology 1991; 74: $1003-6$.

13 Knill RL, Gelb AW. Ventilatory responses to hypoxia and hypercapnia during halothane sedation and anesthesia in man. Anesthesiology 1978; 49: 244-51.

14 Pavlin EG, Holle RH, Schoene RB. Recovery of airway protection compared with ventilation in humans after paralysis with curare. Anesthesiology 1989; 70: 381-5.

15 Orlowski JP. Cerebrospinal fluid endorphins and the infant apnea syndrome. Pediatrics 1986; 78: 233-7.

16 Welborn LG, Hannallah RS, Fink R, Ruttimann UE, Hicks JM. High-dose caffeine suppresses postoperative apnea in former preterm infants. caffeine suppresses postoperative
Anesthesiology 1989; 71: 347-9.

17 Perelman $R$. Reducing iatrogenic lung disease in the premature newborn. Semin Perinatol 1986; 10: 217-23.

18 Spear RM. Anesthesia for premature and term infants: perioperative implications. F Pediatr 1992; 120: 165-76.

19 Abajian JC, Mellish P, Browne AF, Perkins FM, Lambert DH, Mazuzan JE Spinal anesthesia for surgery in the high-risk infant. Anesth Analg 1984 63: 359-62.

20 Harnik EV, Hoy GR, Potolicchio S, Stewart DR, Siegelman RE. Spinal anesthesia in premature infants recovering from respiratory distress syndrome. Anesthesiology 1986; 64: 95-9.

21 Gallagher TM, Crean PM. Spinal anaesthesia in infants born prematurely. Anaesthesia 1989; 44: 434-6.

22 Welborn LG, Rice LJ, Hannallah RS, Broadman LM, Ruttimann UE, Fink $R$. Postoperative apnea in former preterm infants: prospective comparison of spinal and general anesthesia. Anesthesiology 1990; 72: 838-42.

23 Sethna NF, Berde CB. Pediatric regional anesthesia. In: Gregory GA, ed Pediatric anesthesia. New York: Churchill Livingstone, 1989: 647-75.

24 Cox R, Goresky GV. Life-threatening apnea following spinal anesthesia in former premature infants. Anesthesiology 1990; 73: 345-7.

25 Webster AC, McKishnie JD, Kenyon CF, Marshall DG. Spinal anaesthesia for inguinal hernia repair in high-risk neonates. Can $\mathcal{f}$ Anaesth 1991; 38: 281-6.

26 Spear RM, Deshpande JK, Maxwell LG. Caudal anaesthesia in the awake, high-risk infant. Anesthesiology 1988; 69: 407-9.

27 Gunter JB, Watcha MF, Forestner JE, et al. Caudal epidural anesthesia in conscious premature and high-risk infants. F Pediatr Surg 1991; 26 9-14.

28 Peutrell JM, Hughes DG. Epidural anaesthesia through caudal catheters for inguinal herniotomies in awake ex-premature babies. Anaesthesia 1993; 48: $124-31$. 